\title{
"Models of tree and stand dynamics": a differential journey through forest modelling
}

\author{
Gina Marano (1), \\ Alessio Collalti ${ }^{(2-3)}$
}

\begin{abstract}
Models of trees and stands exist since many decades, what nowadays has changed is our focus towards integrated forest ecosystem functioning. Managing forests in the $21^{\text {st }}$ century requires efforts that go beyond empiricism. Annikki Mäkelä and Harry T. Valentine's new book "Models of tree and stand dynamics" (Springer Nature, Cham, 2020) shows the state-of-art for knowledge applied within forest models with useful practical applications. It is a textbook for graduates and scientists interested in process-based models of stand dynamics, growth and forest management. Models represent valuable tools for tackling issues like ecosystem carbon sequestration, helping us understand the economic implications of silvicultural interventions and providing insights on the impacts of climate change on forests. The textbook is a compendium of applied research that non-pure mathematicians can understand, interiorize and take advantage of for getting precious knowledge on forest functioning.
\end{abstract}

\section{Keywords: Forest Modelling, Carbon Balance, Forest Management, Climate Change, Forest Ecology}

Mäkelä A, Valentine HT (2020). Models of tree and stand dynamics. Springer Nature, Cham, Switzerland, pp. 310 [ISBN: 978-3-03035760-3 ]. - doi: 10.1007/978-3-030-35761-0

Forests play a relevant role in the global carbon cycle and this mitigation potential that lies in the accumulated stock of forest ecosystem carbon - has dynamics we either ignore or we are not able to predict completely right now. Could we forecast forest productivity on large geographical areas, under several climate change scenarios? Will forests react to changing environmental conditions? If so, how?

If these questions sound rather familiar, it seems we are aware about the key role of forests and what the challenges in managing forests in the $21^{\text {st }}$ century are. What some might not know, is that none of these issues could ever be faced without models.

Annikki Mäkelä and Harry T. Valentine's new book represents a gentle introduction to the modelling of forest growth based on ecological theory; besides, it is formulated to be sufficiently clear and sharp lending into practical applications. "Models of Tree and Stand Dynamics" is a sound-based textbook that addresses both early (graduate/ doctorate level) but even senior scientists, calling upon "functional" approaches in forest ecology, where particular attention is drawn by reproducing mechanistically and/or empirically eco-physiological processes. Mäkelä \& Valentine's main intent is to teach us, or refresh in some cases our blear memory, to go beyond mathematical models per se; it shows the state-of-art trying at the same time to forecast the $21^{\text {st }}$ century's quantum leap.

This is not the first book addressing forest modelling (see Waring \& Running 2007, Burkhart \& Tomé 2012, Landsberg \& Sands 2011), but is certainly the first one integrating an extensive documentation of theory and concepts and their translation into source codes for a prompt computer programming and testing. Thus, this is not a merely descriptive book and coherently
(1) Department of Agriculture, University of Napoli Federico II, v. Università 100, I-80055 Portici, Naples (Italy); (2) Institute for Agriculture and Forestry Systems in the Mediterranean (ISAFOM), National Research Council of Italy (CNR), I-87036 Rende, CS (Italy); (3) Department of Innovation in Biological, Agro-food and Forest Systems, University of Tuscia, I-01100 Viterbo (Italy)

@ Alessio Collalti (alessio.collalti@cnr.it)

Received: Apr 06, 2020 - Accepted: Apr 13, 2020

Citation: Marano G, Collalti A (2020). "Models of tree and stand dynamics": a differential journey through forest modelling. iForest 13: 152-153. - doi: 10.3832/ifor0061-013 [online 2020-04-16] the authors stated that the description of the plethora of existing forest models can be found elsewhere.

As a premise, the book aims at bridging the gap between empirical and processbased models using mathematical tools and numerical estimations and it perfectly does so by covering a wide range of examples with a rich set of R-codes at the end of each chapter (and including solutions, which were much appreciated). The same, the reader should not be too much concerned about sinking into complex equations, but rather the logic behind is easily comprehensible even from non-pure mathematicians. In this sense, it is more a handbook than a cookbook, because "trees and stands are complex life systems and any attempt to fully describe these systems mathematically is sure to fail". The Mäkelä and Valentine's book is itself the compendium of a whole career as researchers and pioneering modellers, a cradle of lectures material and applied research, from which they drawn up numerous interesting and clarifying examples. The focus is immediately stated: the book mainly covers process-based models that incorporate mechanism, hybridisation, or optimisation, singly or in combination. Yet why? Because our common understanding of stand dynamics, growth and management lacks and is generally limited by a predetermined set of empirical data which we try to rely on.

The first four chapters represent the book's backbone for they provide a synthetic but exhaustive overview of the main concepts and theories, together with elements of carbon balance modelling applied to individual trees (individual tree models), moving then to forest stands (forest stand 
models). A first insight of a real (adapted) tree dynamics model, as synthesis from "pipe-model" (Shinozaki et al. 1964a, Shinozaki et al. 1964b) and carbon-balance theory, is firstly presented in chapter 5 , along with the main allocation rules by which the carbon available for growth is allocated between the components of biomass (leaf, branch, stem, coarse root, and fine root). Chapter 6 deals with individual tree and stand-level competition thus focusing on the challenging issue of resource limitation to total growth and productivity.

Applications of evolutionary optimisation to tree structure and consequent carbon allocation are introduced in chapter 7 altogether with examples of models that use this approach to derive plant structure and carbon allocation (e.g., optimal crown structure, stem shape, etc).

How does forest production vary regionally? Is climate change going to increase or decrease productivity and carbon sequestration? To tackle these issues, go to Chapter 8 which outlines some general ideas and overall accepted theories about linking models with data, moving to input quantification for model applications by introducing different methods of parameterisation for a chosen model (Chapter 5).

Data assimilation is widely used in other rather different fields such as engineering, meteorology and physical oceanography... but it surprisingly happens in forestry research, too. In chapter 9 some basic concepts - central to model calibration - are illustrated, followed by some examples of Bayesian calibration as used in ecological modelling, in comparison with conventional statistical parameter calibration. Two examples of calibrated models for predicting forest growth and estimating carbon balance are also shown. Worth noting, a clear definition (and distinction) of what state variables, parameters and driving (or forcing) variables, including model hierarchical organizations, is provided. What sounds obvious in the theory not often reflects in the practice, and this is even a practical textbook.

There is an increasing demand by national forest policies to assess sustainable harvest levels, forest potential for climate change mitigation, or the supply of roundwood and biomass to the global markets and far more. In this sense, forest modelling represents a valuable toolbox to inspect pressing issues like ecosystem carbon sequestration, economic implications of different silvicultural interventions and policies. In chapter 10 some sound applications of modelling frameworks are provided. In conclusion, we know that models of trees and stands have existed for hundreds of years, but what has changed now is our focus towards integrated ecosystem functioning rather than single tree growth.

Quo vadis then? Forest management recommendations in many countries are based on economical optimization studies that assess the impact of intervention on economic revenue (and costs), trying to find appropriate strategies that are beneficial for the stakeholders. Consequentially, standard optimization studies in forestry are centred and based on empirical growth models. When applied to standard management conditions, these models can offer reliable and reassuring predictions, but at the same time we must be aware that they may lead to serious problems in optimisation "where a solution may be found outside the valid range of model development data or, if restricted, on the border of applicability". And that is often the case in forest management. It is crucial to bridge empirical and process-based data assimilation methods that combine research-based ecological measurements with standard forestry data. Another useful application of process-based stand-level models relies on the possibility to estimate forest productivity in areas not subject to forest inventory. In this case, we should also consider incorporating air-borne measurement methods such as LiDAR, drones, and different varieties of satellite-derived vegetational indexes to drive our models. Nevertheless, the biggest challenge in nowadays forest models - at any level of spatial and temporal resolution - is to make reliable predictions under climate change, especially when not all has been (or can be) accounted for. Major phenomena that deserve more attention here are: (i) changes in sink-source balance due to changes in the annual cycle, and (ii) changes in the carbon and nitrogen $(\mathrm{C}: \mathrm{N})$ balance due to different above-ground and below-ground responses to environmental change (citing Mäkelä \& Valentine 2020), indeed "we know much less about the response of forest soils and nutrient availability under $a$ changing climate". These are our new quantum leaps, hic sunt dracones.

\section{References}

Burkhart HE, Tomé M (2012). Modeling forest trees and stands. Springer Science and Business Media, Dordrecht, Netherlands, pp. 458. doi: 10.1007/978-90-481-3170-9

Landsberg J, Sands P (2011). Physiological ecology of forest production: principles, processes and models (Vol. 4). Elsevier/Academic Press, London, UK.

Mäkelä A, Valentine HT (2020). Models of tree and stand dynamics. Springer Nature, Cham, Switzerland, pp. 310. - doi: 10.1007/978-3-03035761-0

Shinozaki K, Yoda K, Hozumi K, Kira T (1964a). A quantitative analysis of plant form - the pipe model theory. I. Basic analysis. Japanese Journal of Ecology 14: 97-105. [online] URL: http:// www.jstage.jst.go.jp/article/seitai/14/4/14_KJoo 001775220/_article/-char/en

Shinozaki K, Yoda K, Hozumi K, Kira T (1964b). A quantitative analysis of plant form - the pipe model theory. II. Further evidence of the theory and its application in forest ecology. Japanese Journal of Ecology 14: 133-139. [online] URL: http://www.jstage.jst.go.jp/article/seitai/ 14/4/14_KJooo01775220/_article/-char/en Waring RH, Running SW (2007). Forest ecosystems, analysis at multiple scales ( $3^{\text {rd }}$ edn). Academic Press, S. Diego, CA, USA, pp. 370. - doi: 10.1093/treephys/19.2.138 